\title{
Efeitos do aumento da produção de petróleo sobre o potencial de crescimento da economia brasileira: um modelo voltado para a projeção (2013-2020)
}

\author{
André Luís Cabral de Lourenço \\ Professor - Departamento de Economia - Universidade Federal do Rio Grande do Norte (UFRN) \\ Endereço: Caixa Postal 1524 - Campus Universitário Lagoa Nova, Natal/RN - Brasil \\ CEP: 59078-970 - E-mail: andrelc.lourenco@gmail.com
}

\section{Breno Carvalho Roos}

Economista - Secretaria de Estado do Planejamento e das Finanças do Rio Grande do Norte (SEPLAN/RN)

Endereço: Centro Administrativo do Estado - BR 101, Km 0 - Lagoa Nova, Natal/RN - Brasil

CEP: 59064-901 - E-mail: brenoroos@uol.com.br

Recebido em 24 de outubro de 2013. Aceito em 06 de março de 2015.

\section{Resumo}

O artigo provê um modelo voltado para a projeção do potencial de crescimento da economia brasileira, para o período 2013-2020, com particular ênfase na resposta ao aumento previsto para a produção do setor petróleo. Inspirado nos modelos de crescimento de dois e de três hiatos, o modelo em questão inova ao propor conjuntamente: a) tornar endógena a resposta da política econômica, sob o suposto de que o atual "tripé" macroeconômico (câmbio flexível administrado, metas de inflação e de superávit primário) será mantido durante toda a trajetória da simulação; b) tratar separadamente os efeitos do setor petróleo sobre o balanço de pagamentos; e c) verificar a compatibilidade entre a taxa de investimento pública permitida pela meta de superávit primário e aquela necessária para manter o crescimento do estoque de capital em linha com o crescimento do PIB real.

\section{Palavras-Chave}

Modelo de projeção. Economia brasileira. Potencial de crescimento. Setor petróleo.

\begin{abstract}
The article provides a model aimed at the projection of the potential growth of the Brazilian economy for the period 2013-2020, with particular emphasis regarding the expected increase in oil production sector. Inspired by the growth models of two and three gaps, the model in question innovates to jointly propose: al make endogenous the response of economic policy, under the assumption that the current macroeconomic "tripod" (administered flexible exchange, inflation and primary fiscal surplus targets) will be maintained throughout the course of the simulation; b) treat separately the effects of the oil sector on the balance of payments; c) check the compatibility between the public investment rate permitted by primary fiscal surplus target and that required to maintain the stock of capital growth in line with real GDP increase.
\end{abstract}

- Agradecemos os comentários de Ricardo Summa, Fabrício Pitombo Leite, Patieene Passoni e de um parecerista anônimo, que contribuíram para a substancial melhoria do trabalho. Erros remanescentes são de responsabilidade exclusiva dos autores. 


\section{Keywords}

Forecast model. Brazilian economy. Potential growth. Oil sector.

\section{JEL Classification}

O41. 054. 013.

\section{Introdução}

O presente artigo pretende construir um modelo macroeconômico capaz de dar suporte a uma projeção acerca dos efeitos do aumento da produção petrolífera sobre a capacidade de crescimento da economia brasileira. O período coberto pela projeção é o de 2013-2020. ${ }^{1}$

Baseada na tradição do modelo de dois hiatos, a presente modelagem parte do suposto de que as principais limitações ao potencial de crescimento costumam localizar-se nas restrições de balanço de pagamentos e de estoque de capital. Não nega aprioristicamente, contudo, a possibilidade de que, sob certas condições parametrais, também a disponibilidade de mão de obra possa vir a representar um entrave significativo ao crescimento econômico no prazo envolvido. O modelo que se segue não pretende descrever a evolução efetiva da economia brasileira, e sim traçar os possíveis limites dentro dos quais a gestão da demanda agregada poderá atuar. Por consequência, o crescimento da demanda agregada não será modelado, ficando aberta a possibilidade de um desempenho econômico abaixo desses limites devido a um crescimento insuficiente da mesma.

O modelo a seguir desenvolvido adota a suposição fundamental de que a política macroeconômica seguirá, até 2020 , alicerçada no tripé meta de inflação, meta fiscal e câmbio flutuante administrado. Trata-se de uma hipótese acerca da possível evolução da política econômica do Brasil nos próximos anos, e não de uma avaliação a qual de fato seria a melhor política a ser seguida.

O segundo item é dedicado a desenvolver o processo de determinação da taxa de câmbio nominal, associado à dinâmica dos ativos e passivos externos. Dada a importância do câmbio para o processo de formação de preços, o terceiro item busca então estabelecer os ali-

1 Cabe informar que as estimativas já se encontram feitas, mas que devido à extensão do modelo, precisarão ser expostas em outro artigo. 
cerces do processo de formação de preços e, portanto, de determinação da taxa de inflação. O quarto item determina a taxa máxima de crescimento do PIB doméstico, tendo em vista a restrição de balanço de pagamentos. $\mathrm{O}$ quinto item especifica como os aspectos anteriormente desenvolvidos impactam na situação das finanças públicas. $\mathrm{O}$ sexto item sugere como avaliar se a taxa máxima de investimento da economia resultante da restrição fiscal é consistente com a taxa máxima de crescimento permitida pelo balanço de pagamentos. Ele é seguido pelas considerações finais.

\section{Determinação da taxa de câmbio e da dinâmica dos ativos e passivos externos}

A modelagem da conexão entre a taxa de câmbio nominal e a taxa de juros parte da construção de uma "função BP" análoga à do modelo Mundell-Fleming, contudo, com várias alterações significativas.

A hipótese comportamental empregada é a de que, no contexto de relativamente livre mobilidade de capitais (afora a fixação do IOF) e câmbio flutuante administrado, o governo estabelece a trajetória desejada para as reservas internacionais. A conta de capitais se ajusta, através do movimento da taxa de câmbio corrente, para manter o mercado cambial em equilíbrio e o balanço de pagamentos na posição correspondente ao movimento de reservas. De acordo com esta lógica, o mercado cambial se equilibra sem que o balanço de pagamentos fique em equilíbrio - não há mecanismo automático de equilíbrio do balanço de pagamentos em operação. Evidentemente, como as reservas internacionais não podem ser negativas, há um limite para o montante de déficits que podem ser acumulados ao longo do tempo. Afora tal situação, contudo, em geral o balanço de pagamentos será diferente de zero, e o montante de reservas estará em contínua mutação. Em particular, superávits podem se acumular indefinidamente, se e na medida em que o governo resolva manter uma trajetória permanente de crescimento das reservas internacionais.

Convém iniciar pela identidade:

$$
\mathrm{R}_{\mathrm{t}}-\mathrm{R}_{\mathrm{t}-1} \equiv \mathrm{SBP}_{\mathrm{t}} \equiv \mathrm{STC}_{\mathrm{t}}+\mathrm{CCF}_{\mathrm{t}}
$$


onde $\mathrm{R}$ são as reservas internacionais, SBP é o saldo do balanço de pagamentos ("acima da linha"), STC é o saldo em transações correntes e CCF é o saldo da conta de capitais e financeira, todos medidos em US\$ correntes. O saldo em transações correntes é definido como:

$$
S T C_{t} \equiv X_{t}-M_{t}-R L E_{t}
$$

onde $\mathrm{X}$ e $\mathrm{M}$ correspondem, respectivamente, aos níveis de exportações e importações de bens e serviços não fatores, e RLE consiste na renda líquida enviada ao exterior, todos também medidos em US\$ correntes.

Admite-se que:

$$
R L E_{t}=i_{M}^{*} P E L_{t-1}+\overline{R L E}_{t}
$$

onde $i_{M}^{*}$ é o custo (em termos percentuais nominais) da manutenção pelos residentes dos passivos externos líquidos PEL (medido em US $\$$ correntes), ${ }^{2,3}$ e $\overline{R L E}$ é a parte da RLE independente do PEL. ${ }^{4}$ A variável $i_{M}^{*}$ é determinada por:

$$
\mathrm{i}_{\mathrm{M}, \mathrm{t}}^{*}=\sigma_{t}^{*}+i_{t-1}^{*}+\rho_{t-1}^{*}
$$

onde $\sigma^{*}>0$ é um parâmetro, $\mathrm{i}^{*}$ é a taxa de juros externa, e $\rho^{*}$ é o risco país (soberano). A dinâmica do PEL, por sua vez, é gerada a partir de:

$$
P E L_{t} \equiv P E L_{t-1}-S T C_{t}
$$

Juntando as últimas três equações, obtemos:

$$
P E L_{t}=\left(1+i_{M}^{*}\right) P E L_{t-1}-X_{t}+M_{t}+\overline{R L E}_{t}
$$

2 Estamos admitindo, a título de simplificação, que todo o passivo externo líquido é denominado em moeda internacional.

3 Inclusive prêmio de risco. Perceba que se está admitindo, contra factualmente e a título de simplificação, que a remuneração dos ativos externos é idêntica ao custo dos passivos externos. Contudo, perceba que não se trata da taxa corrente, mas da média, o que implica alguma defasagem de resposta às mudanças da política monetária estadunidense.

4 Em princípio, as transferências unilaterais correntes, simuladas como uma fração do PIB do ano anterior medido em dólar. 
Esta última equação determina a trajetória do PEL a partir das trajetórias das exportações e das importações (a ser vista nos itens seguintes) e do valor inicial de PEL.

No que concerne à dinâmica da conta de capitais e financeira, a hipótese fundamental é a de que, embora haja uma mobilidade de capitais relativamente livre (afora o IOF), esta será interpretada contudo como despida da premissa de que os títulos emitidos pelos diferentes países sejam substitutos perfeitos. A consequente existência de risco soberano no modelo acarreta:

$$
\begin{aligned}
& C C F_{t}=\left\{\Psi_{2, \mathrm{t}}+f_{0}+f_{1}\left[\frac{\left(1+i_{t}\right)}{\left(1+i_{t}^{*}\right)\left(1+I O F_{t}\right)\left(1+\rho_{t}^{*}\right)\left(\frac{e_{t+1}^{e}}{e_{t}}\right)}+\right.\right. \\
& \left.\left.\frac{\left(1+\lambda_{t-1}\right)}{\left(1+\lambda_{t-1}^{*}\right)\left(1+\rho_{t}^{*}\right)\left(\frac{e_{t+1}^{e}}{e_{t}}\right)}\right]\right\} Y_{t}^{*}
\end{aligned}
$$

onde $f_{0}, f_{1}>0$ são parâmetros, $Y^{*}$ é o nível do PIB mundial, $\Psi_{2}$ é uma variável aleatória de média zero e distribuição normal, i é a taxa de juros interna, IOF é a alíquota média do Imposto sobre Operações Financeiras, e é a taxa de câmbio nominal esperada, "e" é a taxa de câmbio nominal corrente, ${ }^{5} \lambda$ e $\lambda^{*}$ são, respectivamente, as taxas de lucro no Brasil e no resto do mundo. ${ }^{6,7}$

Considerando tanto a taxa de juros doméstica quanto a internacional como determinadas exogenamente pelos bancos centrais, ${ }^{8}$ a equação determina a trajetória da taxa de câmbio nominal a partir da determinação do diferencial de lucro (a ser tratado mais adiante) e do risco país. Convém associar tal risco a um indicador de liquidez

\footnotetext{
5 A bilateral entre Brasil e EUA.

6 Admite-se que a taxa de lucro dos EUA seja uma boa proxy da taxa de lucro mundial quando se tem em conta que parte significativa do estoque de capital de risco presente no país é de origem estadunidense. $\mathrm{O}$ uso da taxa de lucro defasada justifica-se na medida em que ela representa aparentemente a melhor alternativa para previsão do comportamento da taxa corrente.

7 Como usualmente, a taxa de lucro nacional será determinada por: $\lambda=\frac{Y-W N-T}{P_{k} K_{p, t}}-\delta$. Como estamos supondo que a economia permanece o tempo todo em sua trajetória de crescimento potencial, teremos $K_{p, t}=\frac{v Q}{N U C l}$ o tempo todo.

8 Tal qual em Romer (2000), admite-se que os bancos centrais fixem as taxas básicas de juros e as taxas de mercado sejam formadas pela aplicação de um spread exógeno. Para efeito de simplificação, abstrairemos o processo de formação das taxas de juros, tomando a do modelo como se fosse a formada diretamente pelos bancos centrais.
} 
relacionado ao processo de endividamento externo. O risco soberano será então expresso como:

$$
\rho_{t}^{*}=\rho_{0}+\rho_{1} r_{t-1}^{*}+\rho_{2}\left(\frac{P E B_{t}}{R_{t}}\right)+\Psi_{0, t}
$$

onde $\rho_{0}, \rho_{1}, \rho_{2}>0$ são parâmetros, $\Psi_{0}$ representa choques financeiros externos aleatórios (com média zero e distribuição normal). Como é sabido, as condições financeiras internacionais têm implicações cruciais sobre o risco soberano (p. ex., Ciarlone et alli, 2007), o que explica a presença da taxa de juros externa como proxy das condições de liquidez internacionais.

Para determinar o valor do passivo externo bruto, toma-se a identidade:

$$
P E L_{t} \equiv P E B_{t}-A E B_{t}
$$

onde AEB é o ativo externo bruto. Dividiremos agora os ativos externos brutos em dois subtipos: o ativo externo bruto $A E B_{g}$, de propriedade governamental, e os outros ativos externos brutos, pertencentes aos agentes privados $\left(A E B_{\mathrm{p}}\right)$. $\mathrm{O}$ passivo externo bruto privado, por sua vez, resulta do desdobramento do passivo externo bruto entre as parcelas do setor privado $\left(P E B_{p}\right)$ e do público $\left(P E B_{g}\right)$. Teremos então:

$$
P E L_{t} \equiv P E B_{p, t}+P E B_{g, t}-A E B_{g, t}-A E B_{p, t}
$$

O ativo externo bruto governamental, composto no caso brasileiro em grande parte pelas reservas internacionais $\mathrm{R}$, será modelado como:

$$
A E B_{g, t}=(1+o) R_{t}
$$

onde $o>0$ é um parâmetro que estabelece a (relativamente pequena) fração dos outros tipos de ativos externos sob administração pública em relação às reservas. No que concerne a estas, adota-se a suposição de que a regra de gestão das reservas internacionais seguida pelas autoridades monetárias brasileiras é:

$$
R_{t}=\omega P E B_{t}
$$


onde $\omega$ é uma variável de política econômica tal que $\omega \geq \omega_{\text {MIN }}>0$, e $\omega_{M I N}$ é o valor mínimo permitido pela lei. Tal variável será manejada a todo o instante como o instrumento de primeira linha visando a manter a inflação no centro da meta. Resulta:

$$
P E B_{p, t} \equiv \frac{A E B_{p, t}+P E L_{t}-P E B_{g, t}[1-(1+o) \omega]}{[1-(1+o) \omega]}
$$

Para garantir que $P E B_{p}$ seja estritamente positivo na equação acima, é preciso impor:

$$
A E B_{p} \geq A E B_{p, M I N}=P E B_{g}[1-(1+o) \omega]-P E L_{t},
$$

Esta parte do modelo é então fechada com a expressão comportamental para AEBp:

$$
A E B_{p, t}=\max \left[A E B_{p, t-1}\left(1+\Gamma_{t}\right) ; A E B_{p, M I N}\right],
$$

onde $\Gamma$ é a taxa desejada de crescimento dos ativos externos privados tal que:

$\Gamma_{t}=\Gamma_{0} g_{t-1}+\Gamma_{1}\left[\frac{\left(1+i_{t}^{*}\right)\left(1+\rho_{t}^{*}\right)\left(1+\hat{e}_{t+1}^{e}\right)\left(1+I O F_{t}\right)}{\left(1+i_{t}\right)}\right]+\Gamma_{2}\left[\frac{\left(1+\lambda_{t-1}^{*}\right)\left(1+\rho_{t}^{*}\right)\left(1+\hat{e}_{t+1}^{e}\right)}{\left(1+\lambda_{t-1}\right)}\right]+\Psi_{4, \mathrm{t}}(7)$

onde $\Psi_{4, \mathrm{t}}$ é uma variável aleatória de média zero e distribuição normal, e $\Gamma_{0}, \ldots \Gamma_{2}>0$, são parâmetros.

O passivo externo bruto fica determinado pelas equações acima, considerando que:

- A dinâmica do passivo externo líquido é determinada pela Equação (1);

- As reservas internacionais são variáveis de política econômica;

- O passivo externo bruto governamental depende exclusivamente de decisões de política fiscal acerca do mix de financiamento interno / externo a ser utilizado pelo setor público (vide mais adiante).

Em relação à política monetária, admite-se que o banco central formará a taxa de juros básica tendo em vista, em conjunto com a gestão 
de reservas, manter a taxa de inflação no centro da meta. ${ }^{9}$ Dado portanto o comportamento das reservas, bem como do saldo em transações correntes, a taxa de câmbio nominal ficará determinada pela identidade do balanço de pagamentos, de forma que:

$$
\frac{e_{t}}{e_{t+1}^{e}}=\frac{R_{t}-R_{t-1}-S T C_{t}-\Psi_{2, \mathrm{t}}-f_{0} Y_{t}^{*}}{f_{1}\left[\frac{\left(1+i_{t}\right)}{\left(1+i_{t}^{*}\right)\left(1+I O F_{t}\right)\left(1+\rho_{t}^{*}\right)}+\frac{\left(1+\lambda_{t-1}\right)}{\left(1+\lambda_{t-1}^{*}\right)\left(1+\rho_{t}^{*}\right)}\right] Y_{t}^{*}}
$$

Reconhecendo que no contexto atual (bem como em todo o horizonte de projeção) as reservas internacionais brasileiras permitem ao governo um amplo controle da política cambial, as expectativas cambiais seguem uma lógica convencional baseada nas expectativas acerca das ações governamentais neste campo. Neste contexto, os dados de formação de expectativas da Pesquisa Focus parecem mostram que as expectativas inflacionárias são formadas a partir da taxa pretérita, corrigida pelo diferencial esperado de inflação entre o Brasil e o resto do mundo: ${ }^{10}$

$$
e_{t+1}^{e}=\frac{e_{t-1}\left(1+\pi_{t+1}^{e}\right)}{1+\pi_{t+1}^{e, *}}+\Psi_{1, t}
$$

onde $\pi^{e}$ e $\pi^{e, *}$ são, respectivamente, a taxa de inflação esperada brasileira e estadunidense, e $\Psi_{1}$ é uma variável aleatória com média zero e distribuição normal.

A complexidade na determinação da taxa de inflação (vide próxima seção) induz os agentes a buscarem regras simples, ainda que sabidamente imperfeitas, para a formação das expectativas acerca da inflação futura (Simon, 1958). Contudo, a própria precariedade do estado de confiança em sua formação sujeita tais expectativas a mudanças bruscas (Keynes, 1936, cap. 12). Modelaremos então

9 Como parece estar se tornando praxe na presente gestão do banco central, exceto quando há movimentos para além do teto da inflação, as reservas fornecem a primeira linha de defesa na manutenção da meta de inflação. Elas são reforçadas por mudanças na taxa básica de juros quando o movimento das reservas necessário para estabilizar o câmbio é julgado excessivo. É difícil, porém, estabelecer claramente qual o montante de variação de reservas considerado crítico para o acionamento do instrumento do juro. Parece razoável deixar tal fator a critério da simulação do que estabelecer uma regra rígida.

${ }^{10}$ A inflação esperada do resto do mundo será aproximada pela dos EUA. 
a inflação esperada com base no modelo simples de expectativas adaptativas, porém incluindo um termo de choque:

$$
\pi_{t}^{e}=\Psi_{3, t}+\pi_{t-1}
$$

onde $\Psi_{3}$ é uma variável aleatória com média zero e distribuição normal. O item seguinte determinará o comportamento da taxa de inflação efetiva.

A consideração das equações acima, em conjunto com as equações para as exportações e importações (item 3), permitirá obter a dinâmica do setor externo da economia ao longo de toda a simulação.

\section{Formação de preços e inflação}

Passemos à modelagem do processo de formação de preços e inflação. Desdobremos o processo em dois subconjuntos de preços, os dos produtos do setor petróleo (petróleo bruto e derivados, com subscritos p) e os do setor não petróleo (com subscritos np).

$$
\pi_{t}=p_{t-1} \pi_{p, t}+\left(1-p_{t-1}\right) \pi_{n p, t}
$$

onde $\pi$ é a taxa de variação dos preços no Brasil (IPCA); $p$ é o peso (móvel) do valor agregado do setor petrolífero no PIB. Perceba que no caso brasileiro, dado o peso da Petrobrás na formação dos preços do petróleo, convém tomar $\pi_{p}$ como:

$$
\pi_{p, t}=\left[1+\hat{\mathrm{e}}_{t}\right]\left[1+\overline{\pi_{p}^{*}}+\gamma\left(\pi_{p, t}^{*}-\overline{\pi_{p}^{*}}\right)\right]-1
$$

onde $\overline{\pi_{p}^{*}}$ é a tendência (exógena) de longo prazo de evolução dos preços do setor petróleo, e $0 \leq \gamma \leq 1$ é um coeficiente de amortecimento do repasse dos desvios de crescimento dos preços internacionais do petróleo de sua tendência, para os preços domésticos desse setor. Gama depende da política do governo no que concerne à gestão dos preços dos combustíveis.

Perceba que no caso extremo $\gamma=1$ não haveria amortecimento, e todas as variações de preço seriam internalizadas $\left(\pi_{p, t}^{*}\right)$; no extremo oposto, apenas as mudanças de longo prazo $\left(\overline{\pi_{p}^{*}}\right)$ seriam repassadas. 
A política de preços prevista na fórmula funciona em ambos os sentidos: quando os preços internacionais do petróleo sobem mais rápido do que a tendência de longo prazo $\left(\pi_{p, t}^{*}>\overline{\pi_{p}^{*}}\right)$, se a taxa de câmbio não mudar os preços nacionais sobem mais lentamente do que os externos. Mas quando ocorre o movimento inverso, eles também caem mais lentamente. Tal política, portanto, desde que seguida de forma simétrica (é o suposto aqui adotado), implicaria um repasse integral na média de vários períodos $\pi_{p, t}=\left[1+\hat{\mathrm{e}}_{t}\right]\left[1+\overline{\pi_{p}^{*}}\right]$.

O peso do setor petróleo na economia nacional evoluirá na simulação de acordo com a proxy:

$$
p_{t}=\frac{Y_{p, t-1}\left(1+\pi_{p, t}\right)\left(1+g_{p, t}^{p}\right)}{Y_{t-1}\left(1+\pi_{t}\right)\left(1+g_{t}\right)}
$$

onde Y é o PIB nominal, Yp é o produto nominal do setor petróleo, $g_{p}^{p}$ é a taxa de crescimento da produção física do setor petróleo, g é a taxa de crescimento do PIB real, Pp é o nível de preços do setor petróleo e Qp é o nível real de produto do mesmo setor.

A formação doméstica dos preços do setor não petróleo, ${ }^{11}$ por sua vez, pode ser modelada conforme:

$$
\pi_{n p, t}=\tau_{t}\left(\hat{\mathrm{e}}_{t}+\pi_{t}^{*}\right)+\left[1-\tau_{t}\right]\left[\frac{\left(1+\hat{z}_{t}\right)\left(1+\widehat{W}_{t}\right)}{\left(1+\hat{a}_{t}\right)}-1\right]
$$

onde $\tau$ é o peso dos bens comercializáveis no setor não petróleo, $\widehat{W}$ é a taxa de variação dos salários nominais, $\hat{a}$ é a taxa de crescimento da produtividade do trabalho e $\hat{z}$ representa variações na margem de lucro e/ou a presença de outros choques de oferta. ${ }^{12}$ Tratemos de cada um dos desses componentes. O comportamento do peso $\tau$ é descrito por:

$$
\tau_{t}=\tau_{0} \theta_{t-1}^{\tau_{1}}
$$

onde $\tau_{0}, \tau_{1}$ são parâmetros e $\theta$ é a taxa de câmbio real. No que concerne aos salários, adota-se:

\footnotetext{
${ }^{11}$ A formação externa de preços do setor não petróleo será tomada como exógena, e obtida a partir de projeções internacionais.

12 A ausência de um componente relacionado ao custo tributário explica-se pela hipótese de ausência de mudança na carga tributária líquida ao longo de todo o tempo da simulação.
} 


$$
\widehat{W}_{t}=\alpha_{0}+\alpha_{1} \pi_{t-1}+\alpha_{2} \hat{W}_{M I N, t}-\alpha_{3}\left(u_{t}-u_{t-1}\right)+\alpha_{4} \hat{a}_{t}
$$

onde $\alpha_{0}$ representa choques salariais exógenos, enquanto os demais alfas são parâmetros estritamente positivos (com $0 \leq \alpha_{1}, \alpha 4, \leq 1$ ); $\widehat{W}_{M I N}$ é a taxa de crescimento do salário mínimo, e u é a taxa de desemprego. ${ }^{13}$ Salienta-se: a) a não imposição (heterodoxa) de $\alpha_{1}=1$, bem como a ausência de um termo expectacional para a inflação, a ser justificado ao final do item; b) o uso da variação da taxa de desemprego, e não de seu nível, como argumento da função.

A regra de crescimento do salário mínimo será:

$$
\widehat{W}_{M I N, t}=\left(1+\pi_{t-1}\right)\left(1+g_{t-1}\right)-1
$$

A taxa de crescimento da produtividade do trabalho seguirá a célebre lei de Verdoorn, expandida para:

$$
\hat{a}_{t}=\hat{a}_{0}+\hat{a}_{1} g_{t}+\hat{a}_{2}\left(\frac{\hat{W}}{P}\right)_{t-1}
$$

onde $\hat{a}_{0}$ é a taxa autônoma de crescimento da produtividade do trabalho, $0<\hat{a}_{1} \ll 1$ é o "coeficiente de Verdoorn", um parâmetro que representa a intensidade dos ganhos dinâmicos de escala, $\left(\frac{\hat{W}}{P}\right)$ é a taxa de crescimento dos salários reais e $\hat{a}_{2}>0$ é um parâmetro. ${ }^{14}$

Por definição, a taxa de desemprego é dada por:

$$
u_{t} \equiv \frac{P E A_{t}-N_{t}}{P E A_{t}}
$$

onde PEA é o tamanho da População Economicamente Ativa, e N é o nível de emprego. Este último é determinado por:

$$
N_{t}=\frac{Q_{t-1}\left(1+g_{t}\right)}{a_{t}}
$$

\footnotetext{
${ }^{13}$ A formulação de que a taxa de crescimento dos salários depende da variação, e não do nível do desemprego, é consistente com a hipótese de histerese obtida a partir da Curva de Salários, desenvolvida por Blanchflower e Oswald (1994) e consistente com Lavoie (1992). Para aplicação ao Brasil vide Santolim e Antigo (2009).

${ }^{14}$ Para uma justificativa da introdução desse termo, vide Nastepaad (2006).
} 
onde Q é o PIB real, e $\alpha$ é o nível de produtividade do trabalho, determinado a partir da identidade:

$$
a_{t} \equiv a_{t-1}\left(1+\hat{a}_{t}\right)
$$

Para concluir a determinação da taxa de desemprego, falta determinar o comportamento da PEA. Partindo da definição da proporção $j$ (proxy da taxa de participação):

$$
j_{t}=\frac{P E A_{t}}{P O P_{t}}
$$

onde POP é o tamanho da população, se obtém:

$$
j_{t}=j_{0}+j_{1} j_{t-1}+j_{2} t+j_{3}\left(\frac{W}{P}\right)_{t-1}+j_{4} u_{t-1}^{2}
$$

onde todos os jotas são parâmetros. Aqui aparece um elemento interessante de flexibilidade no modelo, que visa a captar alguns fatos estilizados, quais sejam: a) o efeito do salário real sobre a oferta de trabalho é dúbio, cabendo ao sinal de $j_{3}$ estabelecer a prevalência dos efeitos renda ou substituição em termos empíricos; b) o mesmo ocorre para o efeito da taxa de desemprego na taxa de participação: um aumento do desemprego pode reduzir a taxa de participação (efeito desalento) ou aumentá-la, caso a perda do emprego por parte de um membro da família leve os demais a procurarem emprego no intuito de defesa da renda familiar. A presença do elemento quadrático sugere que a prevalência de um ou outro efeito pode depender da faixa de desemprego atingida.

A população crescerá a uma taxa exógena $\Omega$ :

$$
P O P_{t}=P O P_{t-1}\left(1+\Omega_{\mathrm{t}}\right)
$$

No que concerne ao movimento das margens de lucro, temos: ${ }^{15}$

$$
\hat{z}_{t}=\hat{z}_{0}+\hat{z}_{1}\left(i_{t-1}-i_{t-2}\right)+\hat{z}_{2}\left(N U C I_{t}-N U C I_{t-1}\right)
$$

onde $\hat{Z}_{0}$ é o componente autônomo de choques de oferta no setor de não comercializáveis, ${ }^{16} \hat{Z}_{1}$ é um parâmetro que capta o efeito direto das taxas de juros sobre suas margens de lucro, ${ }^{17}$ NUCI é o nível de

\footnotetext{
${ }^{15} \mathrm{O}$ longo período da simulação justifica a omissão do efeito catraca na relação preços/margens.

16 Variável aleatória com média zero e distribuição normal.

17 Justificável tanto nos termos de Sraffa quanto nos de Keynes.
} 
utilização da capacidade instalada, e $\hat{Z}_{2}$ capta o possível caráter prócíclico (caso $\hat{Z}_{2}>0$, devido, por exemplo, à presença dos preços flex) ou anticíclico (caso $\hat{Z}_{2}<0$, conforme Kalecki, 1954) das margens. Parece interessante sintetizar os vários determinantes da inflação no Quadro 1 a seguir.

Convém comentar alguns sinais incomuns para as derivadas parciais. Observa-se inicialmente que em função do impacto direto sobre a margem de lucro, aumentos da taxa de juros poderiam possuir impacto positivo sobre a taxa de inflação. Contudo, provavelmente o impacto negativo sobre a inflação através do câmbio prevalece. Ademais, tendo em vista que o comportamento da demanda agregada não foi considerado na modelagem, tampouco é captada uma segunda possível fonte de efeitos redutores de uma alta dos juros sobre a inflação, qual seja, via demanda, se as margens forem de fato pro-cíclicas.

É interessante ainda comentar a complexa relação entre o crescimento $\left(g_{t-1}\right)$ e a inflação corrente, dada a multiplicidade de canais que os conectam. Além da relação-chave que relaciona o crescimento do produto ao das importações, e desta (via câmbio) à inflação, há outras três vias de transmissão entre as duas variáveis: margens de lucro; salários; e produtividade, todas elas relacionadas aos produtos não comercializáveis.

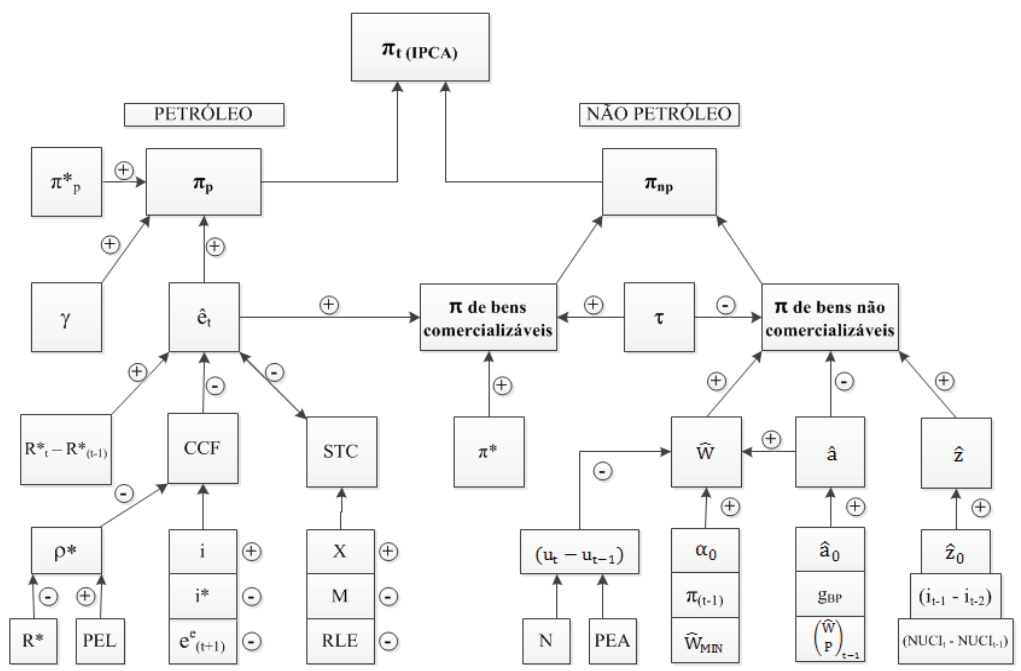

Quadro 1: Síntese dos principais determinantes da taxa de inflação. 
Pela via da produtividade, um aumento do crescimento tende a reduzir a inflação, posto que os ganhos dinâmicos de escala deles decorrentes promovem uma tendência de crescimento da produtividade e, portanto, queda dos custos unitários.

Pela via das margens de lucro, a relação é dúbia, mais uma vez devido à incerteza acerca do caráter pró ou anticíclico das mesmas. Se prevalecer uma relação pró-cíclica, um maior crescimento pressionará a inflação pela via dos preços flex. O oposto se dará em caso de prevalência do caráter anticíclico, quando então a tendência de redução do grau de monopólio se fará sentir com maior intensidade.

Finalmente, um crescimento mais acelerado fará crescer o emprego, reduzindo a taxa de desemprego, fortalecendo o poder de barganha dos trabalhadores e, portanto, elevando a taxa de crescimento dos salários nominais e a inflação. Mesmo essa via, contudo, revela a existência de fatores de amortecimento, quais sejam: a) a própria redução da taxa de desemprego pode aumentar a taxa de participação, o que amortece o ganho de poder de barganha dos trabalhadores; b) o aumento de salário real que costuma ceteris paribus acompanhar a subida dos salários nominais pode aumentar a taxa de participação, contendo a própria tendência de crescimento dos salários nominais; c) o crescimento da produtividade, acelerado através da lei de Verdoorn, tende a amortecer o crescimento dos custos salariais decorrentes do aumento dos salários; ainda quando os salários tendam a aumentar mais pelo próprio efeito do crescimento da produtividade, este efeito pode ainda gerar amortecimento se $\alpha_{4}<1$.

A dubiedade decorrente de tal multiplicidade de efeitos, contudo, provavelmente cederá conforme considerarmos, mais adiante, os efeitos de um crescimento mais acelerado sobre o crescimento das importações. A consequente pressão contínua pela depreciação cambial, com impactos inflacionários, tenderá a fazer pender a balança dos efeitos do aumento do crescimento no sentido direto, e o sinal da derivada parcial muito provavelmente passará a ser positivo. 


\section{A taxa de crescimento máxima permitida pelo balanço de pagamentos}

A restrição externa manifesta-se no presente modelo em dois estágios: 1) dada a política de reservas escolhida, pela existência de uma limitação ao endividamento externo sustentável, representada pela existência de uma relação passivo externo líquido / exportações máxima $d_{M A X}{ }^{18}$; 2) dado o impacto inflacionário das depreciações cambiais, pela existência de um sistema de meta de inflação que limita o uso da política cambial (via elevação da relação reservas internacionais / passivo externo bruto) e da monetária (via taxa de juros básica) para amenizar a restrição externa.

A equação para a relação $d=$ passivo externo líquido / exportações é obtida a partir de (1):

$$
\begin{aligned}
d_{t}=\frac{P E L_{t}}{X_{t}} & =\frac{\left(1+i_{M}^{*}\right) P E L_{t-1}-X_{t}+M_{t}+\overline{R L E}_{t}}{X_{t}} \\
& =\frac{\left(1+i_{M}^{*}\right) P E L_{t-1}+M_{t}+\overline{R L E}_{t}}{X_{t}}-1
\end{aligned}
$$

Para desenvolvê-la, convém usar as definições de taxa de crescimento das exportações $(\hat{X})$ e das importações $(\hat{M})$, adequadamente desdobradas entre os componentes petróleo e não petróleo, considerando os pesos relativos desses setores nas exportações $(\mathbb{x} p)$ e nas importações $(\operatorname{mm} p)$ :

$$
\begin{aligned}
& X_{p, t} \equiv X_{p, t-1}\left(1+\hat{X}_{p, t}\right) \equiv \mathbb{x}_{p, t-1} X_{t-1}\left(1+\hat{X}_{p, t}\right) \\
& M_{p, t} \equiv M_{p, t-1}\left(1+\hat{M}_{p, t}\right) \mathrm{m}_{p, t-1} M_{t-1}\left(1+\hat{M}_{p, t}\right) \\
& X_{n p, t} \equiv X_{n p, t-1}\left(1+\hat{X}_{n p, t}\right) \equiv X_{t-1}\left(1-\mathbb{x}_{p, t-1}\right)\left(1+\hat{X}_{n p, t}\right) \\
& M_{n p, t} \equiv M_{n p, t-1}\left(1+\hat{M}_{n p, t}\right)\left(1-\mathrm{m}_{p, t-1}\right) M_{t-1}\left(1+\hat{M}_{n p, t}\right)
\end{aligned}
$$

\footnotetext{
${ }^{18}$ Definida como aquela capaz de sustentar-se diante de qualquer contingência plausível de "parada súbita" do crédito internacional para o país.
} 
A aplicação das seguintes definições permite agora separar os termos reais e nominais:

$$
\begin{aligned}
& \hat{M}_{p, t} \equiv\left(1+m_{p, t}\right)\left(1+\pi_{m p, t}^{*}\right)-1 \\
& \widehat{M}_{n p, t} \equiv\left(1+m_{n p, t}\right)\left(1+\pi_{m n p, t}^{*}\right)-1 \\
& \hat{X}_{p, t} \equiv\left(1+x_{p, t}\right)\left(1+\pi_{x p, t}^{*}\right)-1 \\
& \hat{X}_{n p, t} \equiv\left(1+x_{n p, t}\right)\left(1+\pi_{x n p, t}^{*}\right)-1
\end{aligned}
$$

onde $m$ e $x$ são as taxas de crescimento real (US $\$$ constantes) das importações e exportações, respectivamente; e $\pi_{m}^{*}$ e $\pi_{x}^{*}$ são as taxas de variação dos preços (US\$) das importações e das exportações, respectivamente.

Tomaremos a variação dos preços (US\$) das exportações e das importações, tanto petróleo como não petróleo, como geradas exogenamente. ${ }^{19}$ Convém agora aplicar as fórmulas típicas para as taxas de crescimento reais das exportações e importações não petróleo nos moldes Kaldor/Thirlwall:

$$
\begin{aligned}
& m_{n p, t}=\eta_{m n p}\left(\pi_{n p, t-1}-\hat{\mathrm{e}}_{t-1}-\pi_{m n p, t-1}^{*}\right)+\xi_{m n p} g_{t} \\
& x_{n p, t}=\eta_{x n p}\left(\hat{\mathrm{e}}_{t-1}+\pi_{x n p, t-1}^{*}-\pi_{n p, t-1}\right)+\xi_{x n p} g_{t}^{*}
\end{aligned}
$$

onde $\eta_{m}, \eta_{x}>0$ são, respectivamente, as elasticidades-preço da demanda por importações e exportações (em valor absoluto); $\xi_{m}, \xi_{x}>0$ são, respectivamente, as elasticidades-renda da demanda por importações e exportações; e $g^{*}$ é a taxa de crescimento do PIB real mundial. ${ }^{20}$ Perceba que, diferentemente de Thirlwall, estamos supondo, em linha com Kaldor, que as demandas por exportações e importações não petróleo possam responder às variações de preços relativos (neste caso, a variações da taxa de câmbio real, o que equivale ao termo entre parênteses na equação). Como o que interessa contudo para efeito de balanço de pagamentos são as exportações e importações em dólar (Behring, 2013), perceba que - dada a hipó-

19 A partir das previsões internacionais.

20 Empregada aqui como proxy da taxa de crescimento dos principais parceiros comerciais. 
tese de país "pequeno" - a possibilidade de violação da condição de Marshall-Lerner não se manifesta.

Justifica-se o emprego da abordagem kaldoriana nesse aspecto não porque rejeitemos a possibilidade de que no longo prazo a taxa de câmbio real seja constante, ou mesmo de que a elasticidade-preço das exportações e importações seja insignificante. O período de tempo da simulação parece curto o suficiente para a manutenção da possibilidade de que variações do câmbio real sejam capazes de afetar as taxas de crescimento das exportações e importações. Adota-se, contudo, uma defasagem de resposta das exportações e importações à mudança cambial de um ano. Tal prazo parece estar razoavelmente em linha com os achados empíricos recentes. ${ }^{21}$

No que concerne à modelagem das exportações e importações de petróleo, convém iniciar pela tautologia:

$$
x_{p, t} \equiv g_{p, t}^{p}+m_{p, t}-g_{p, t}^{d},
$$

onde $g_{p, t}^{d}$ é a taxa de crescimento real da demanda doméstica por petróleo, e $g_{p, t}^{p}$ é a taxa de crescimento real da produção doméstica de petróleo. A interpretação desta equação é a seguinte: considerando que o crescimento da produção física petrolífera (inclusive pré-sal) estará restrito pela oferta no prazo da simulação, ${ }^{22}$ e dadas as equações comportamentais (a seguir) que descrevem o comportamento da demanda doméstica por petróleo (local e importado), obtém-se como resíduo a taxa de crescimento real das exportações de petróleo. ${ }^{23}$

$$
\begin{aligned}
& g_{p, t}^{d}=\eta_{p}\left(\pi_{n p, t-1}-\pi_{p, t-1}\right)+\xi_{p} g_{t} \\
& m_{p, t}=\eta_{m p}\left(\pi_{p, t-1}-\hat{\mathrm{e}}_{t-1}-\pi_{p, t-1}^{*}\right)+\xi_{m p}\left(g_{p, t}^{d}+x_{p, t}-g_{p, t}^{p}\right), \mathrm{ou} \\
& m_{p, t}=\eta_{m p}\left(\pi_{p, t-1}-\hat{\mathrm{e}}_{t-1}-\pi_{p, t-1}^{*}\right)+\xi_{m p}\left[\eta_{p}\left(\pi_{n p, t-1}-\pi_{p, t-1}\right)\right. \\
& \left.+\xi_{p} g_{t}+x_{p, t}-g_{p, t}^{p}\right],
\end{aligned}
$$

\footnotetext{
${ }^{21}$ Vide por exemplo Marçal et alli (2009).

${ }^{22}$ A variável limitante aqui é o montante de investimentos no setor petróleo, em particular os da Petrobras.

${ }^{23}$ Isto implica supor que o país seja um "pequeno produtor", no sentido de que sua produção é incapaz de afetar significativamente os preços internacionais do petróleo. O mercado internacional de petróleo absorverá, ao preço internacional vigente, qualquer quantidade de petróleo que o país se dispuser a exportar.
} 
onde $\eta_{p}>0$ é o valor absoluto da elasticidade preço (doméstica e externa) da demanda por petróleo; e $\xi_{p}>0$ é a elasticidade renda doméstica da demanda por petróleo. Mais uma vez, supõe-se que a resposta das demandas (por petróleo local e importado) às variações de preços relativos ocorre com uma defasagem de um ano.

Substituindo as duas últimas equações na anterior, obtemos:

$$
x_{p, t}=g_{p, t}^{p}-\eta_{p}\left(\pi_{n p, t-1}-\pi_{p, t-1}\right)-\xi_{p} g_{t}+\frac{\eta_{m p}\left(\hat{\mathrm{e}}_{t-1}+\pi_{p, t-1}^{*}-\pi_{p, t-1}\right)}{\left(1-\xi_{m p}\right)}
$$

Para simplificar a notação, é conveniente adotar:

$$
\begin{aligned}
& \hat{\theta}_{p, t-1}=\hat{\mathrm{e}}_{t-1}+\pi_{p, t-1}^{*}-\pi_{p, t-1} ; \\
& \hat{\theta}_{x n p, t-1}=\hat{\mathrm{e}}_{t-1}+\pi_{x n p, t-1}^{*}-\pi_{n p, t-1} ; \\
& \hat{\theta}_{m n p, t-1}=\hat{\mathrm{e}}_{t-1}+\pi_{m n p, t-1}^{*}-\pi_{n p, t-1} ; \mathrm{e} \\
& \hat{\theta}_{n p, t-1}=\pi_{n p, t-1}-\pi_{p, t-1},
\end{aligned}
$$

Implicando:

$$
\begin{aligned}
& m_{n p, t}=-\eta_{m n p} \hat{\theta}_{m n p, t-1}+\xi_{m n p} g_{t} \\
& x_{n p, t}=\eta_{x n p} \hat{\theta}_{x n p, t-1}+\xi_{x n p} g_{t}^{*} \\
& m_{p, t}=-\eta_{m p} \hat{\theta}_{p, t-1}+\xi_{m p}\left[\eta_{p} \hat{\theta}_{n p, t-1}+\xi_{p} g_{t}+x_{p, t}-g_{p, t}^{p}\right] \\
& x_{p, t}=g_{p, t}^{p}-\eta_{p} \hat{\theta}_{n p, t-1}-\xi_{p} g_{t}-\frac{\eta_{m p} \hat{\theta}_{p, t-1}}{\left(1-\xi_{m p}\right)}
\end{aligned}
$$

Das últimas equações resulta:

$$
\begin{aligned}
& X_{p, t} \equiv X_{p, t-1}\left\{\left[1+g_{p, t}^{p}-\eta_{p} \hat{\theta}_{n p, t-1}-\xi_{p} g_{t}-\frac{\eta_{m p} \hat{\theta}_{p, t-1}}{\left(1-\xi_{m p}\right)}\right]\left[1+\pi_{x p, t}^{*}\right]\right\} \\
& M_{p, t} \equiv M_{p, t-1}\left\{\left[1-\eta_{m p} \hat{\theta}_{p, t-1}+\xi_{m p}\left(x_{p, t}+\eta_{p} \hat{\theta}_{n p, t-1}+\xi_{p} g_{t}-g_{p, t}^{p}\right)\right]\right. \\
& \left.\left[1+\pi_{m p, t}^{*}\right]\right\}
\end{aligned}
$$




$$
\begin{aligned}
& X_{n p, t} \equiv X_{n p, t-1}\left\{\left[1+\eta_{x n p} \hat{\theta}_{x n p, t-1}+\xi_{x n p} g_{t}^{*}\right]\left[1+\pi_{x n p, t}^{*}\right]\right\} \\
& M_{n p, t} \equiv M_{n p, t-1}\left\{\left[1-\eta_{m n p} \hat{\theta}_{m n p, t-1}+\xi_{m n p} g_{t}\right]\left[1+\pi_{m n p, t}^{*}\right]\right\}
\end{aligned}
$$

Para obter a taxa máxima de crescimento permitida pelo balanço de pagamentos, é preciso impor $d_{t}=d_{\text {MAX }}$. Substituindo as Equações (41-44) em (19):

$$
\frac{g_{B P, t}=\frac{\left\|1+d_{M A X}\right\|\left\|X_{p, t-1}\left\{\left[1+g_{p, t}^{p}-\eta_{p} \hat{\theta}_{n p, t-1}-\frac{\eta_{m p} \hat{\theta}_{p, t-1}}{\left(1-\xi_{m p}\right)}\right]\left[1+\pi_{x p, t}^{*}\right]\right\}+X_{n p, t}\right\|}{\left[M_{n p, t-1}\left(1+\pi_{m n p, t}^{*}\right) \xi_{m n p}+X_{p, t-1}\left(1+\pi_{x p, t}^{*}\right) \xi_{p}\left(1+d_{M A X}\right)\right]}}{-P E L_{t-1}+R L E_{t}-M_{p, t}-M_{n p, t-1}\left\{\left[1-\eta_{m n p} \hat{\theta}_{m n p, t-1}\right]\left[1+\pi_{m n p, t}^{*}\right]\right\}}
$$

As principais determinantes da taxa máxima de crescimento permitida pela restrição externa $\left(\mathrm{g}_{\mathrm{BP}}\right)$ estão sumarizadas no Quadro 2 a seguir.

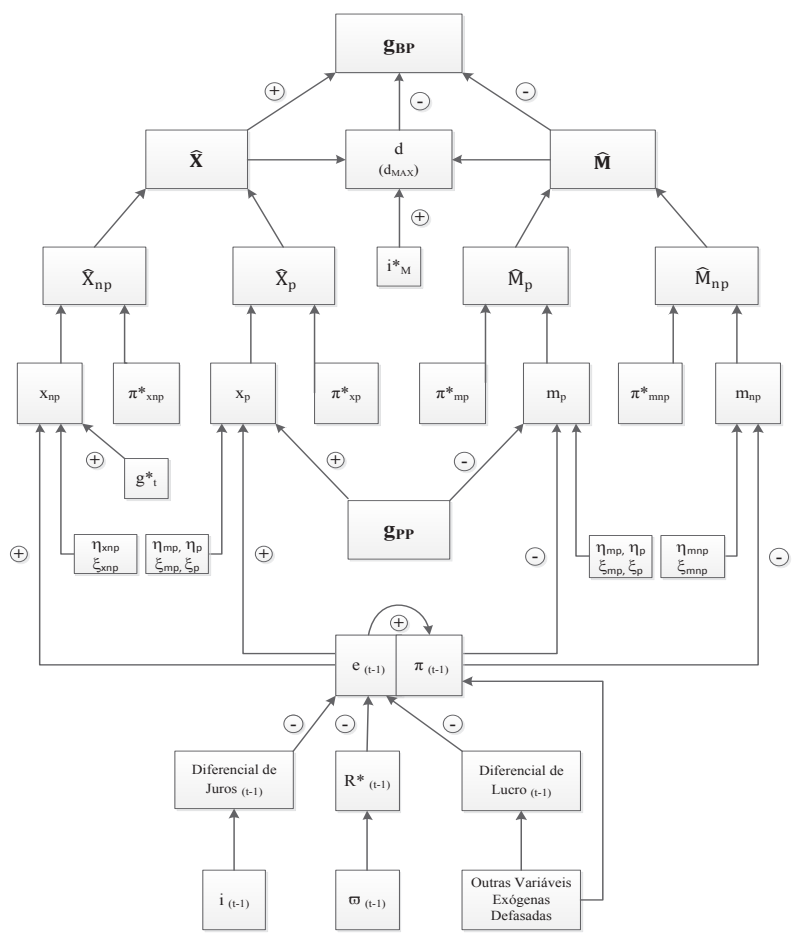

Quadro 2: Síntese dos principais determinantes da taxa de crescimento máxima permitida pelo balanço de pagamentos $\left(\mathrm{g}_{\mathrm{BP}}\right)$ : 
As maiores novidades na determinação de $g_{B P}$ em relação ao modelo de Kaldor são:

a) Uma maior taxa de crescimento da produção de petróleo aumenta $\mathrm{g}_{\mathrm{BP}}$, pois o crescimento mais rápido da produção de petróleo gera crescimento mais rápido das exportações do setor petróleo;

b) $\mathrm{O}$ denominador da fração não depende apenas de uma elasticidade-preço genérica da demanda por importações, mas de uma média ponderada entre a elasticidade-preço da demanda por importações não petróleo e a elasticidade-preço da demanda específica por petróleo, ponderadas pelas taxas de variação dos respectivos preços em dólar e pelos respectivos pesos nas importações;

c) Ao invés de apenas uma taxa de câmbio real, há quatro preços relativos diferenciados cuja evolução afeta $\mathrm{g}_{\mathrm{B} P}$ : o do petróleo (diretamente); o das exportações não petróleo (diretamente); o das importações não petróleo (inversamente); e o preço relativo doméstico entre os setores não petróleo e petróleo (inversamente).

d) A introdução do grau de endividamento externo prévio e do custo do passivo externo na análise: quanto menor o grau de endividamento prévio $\left(d_{t-1}\right)$ em relação ao máximo considerado seguro $\left(d_{\text {MAX }}\right)$, e quanto menor o custo do passivo externo líquido $\left(i_{M}^{*}\right)$, maior $g_{B P}$.

\section{Situação patrimonial-financeira do setor público}

Passamos agora a estender o modelo para estimar o impacto fiscal do crescimento da produção de petróleo. Para tanto, convém estabelecer a identidade patrimonial do setor público, a qual exige, por sua vez, a definição dos fatores a serem considerados na análise. No campo dos ativos, assumiremos que o setor público brasileiro se ocupa basicamente de dois grandes conjuntos: um externo (ativo externo bruto, que inclui as reservas internacionais) e um interno (ativo financeiro doméstico). ${ }^{24}$ Em relação aos passivos, o setor pú-

${ }^{24}$ Convém lembrar que o conceito de dívida líquida do setor público empregado atualmente no país não considera os ativos e passivos do setor público financeiro (Bacen, 2012), o que justifica a exclusão do movimento do crédito pelo setor público financeiro da análise. 
blico brasileiro ostenta a base monetária, a dívida pública interna (denominada em moeda nacional) e o passivo externo bruto (suposto como integralmente denominado em moeda estrangeira). A diferença entre passivos e ativos representa a dívida líquida do setor público $(D L S P)$, definida em termos nominais como:

$$
D L S P_{t} \equiv H_{t}+D g_{t}+e_{t}\left(P E B g_{t}^{*}-A E B g_{t}^{*}\right)-A_{t}
$$

onde $H$ é a base monetária, $D g$ é a dívida interna bruta, $A$ e representa os ativos financeiros domésticos do setor público. Imediatamente se estabelece a conexão entre o estoque de DLSP e o fluxo de resultados fiscais através das necessidades de financiamento do setor público (NFSP):

$$
D L S P_{t} \equiv D L S P_{t-1}+N F S P_{t}
$$

Esta última variável, por sua vez, é definida por:

$$
N F S P_{t}=P k_{t} I g_{t}-\left[T_{t}-T r_{t}-J g_{t}-R L E g_{t}-C g_{t}\right]
$$

onde Pk é o índice de preço dos bens de capital, Ig é a formação bruta de capital fixo do setor público, $\mathrm{C} g$ é seu consumo, $T$ é a arrecadação bruta de impostos, ${ }^{25} \operatorname{Tr}_{t}$ são as transferências governamentais para o setor privado (exceto juros), $J g$ são os juros nominais líquidos sobre a dívida pública interna líquida $(\mathrm{Dg}-\mathrm{A})$ e $R L E g_{t}$ é a renda líquida enviada ao exterior pelo governo.

Temos ainda que:

$$
\begin{aligned}
& J g_{t}=i_{D, t} D g_{t-1}-i_{A, t} A_{t-1} \\
& R L E g_{t}=e_{t}\left(i_{P, t}^{*} P E B g_{t-1}^{*}-i_{A, t}^{*} A E B g_{t-1}^{*}\right),
\end{aligned}
$$

onde $i_{D}$ é a taxa de juros incidente sobre a dívida pública interna, ${ }^{26}$ $i_{A}$ é a taxa de juros recebida sobre os ativos financeiros do setor

\footnotetext{
${ }^{25}$ Descontados os subsídios e incluindo os lucros das estatais não financeiras, exceto Petrobras e Eletrobras.

${ }^{26}$ Trata-se da média das taxas básicas passadas, ponderadas pelo peso dos títulos da dívida pública emitidos em cada período passado no total da dívida pública.
} 
público, ${ }^{27} \boldsymbol{i}_{p}^{*}$ é o custo financeiro do passivo externo bruto do setor público, e $i_{A}^{*}$ é a taxa de retorno recebida sobre seu ativo externo bruto. ${ }^{28}$

Resulta:

$$
\begin{aligned}
& \operatorname{NFSP}_{t}=P k_{t} I g_{t}-\left[T_{t}-\operatorname{Tr}_{t}-i_{D, t} D g_{t-1}+i_{A, t} A_{t-1}\right. \\
& \left.-e_{t}\left(i_{P, t}^{*} P E B g_{t-1}^{*}-i_{A, t}^{*} A E B g_{t-1}^{*}\right)-C g_{t}\right]
\end{aligned}
$$

O comportamento da base monetária deve ser compreendido a partir das identidades:

$$
H_{t} \equiv \frac{M P_{t}}{m m_{t}} ; \text { e } M P_{t} \equiv \frac{Y_{t}}{V_{t}}
$$

onde $m m>0$ é o multiplicador monetário, $M P_{t}$ são os meios de pagamento, e $V_{t}$ é a velocidade-renda de circulação da moeda. Resulta:

$$
H_{t} \equiv \frac{Y_{t}}{m m_{t} V_{t}}
$$

A interpretação desta identidade deve levar em conta o fato de que a política monetária opera via estabelecimento da taxa de juros básica, implicando meios de pagamento e base monetária endógenos. Tal fenômeno se dá tanto por seus efeitos internos quanto externos (esterilização dos efeitos do saldo do balanço de pagamentos sobre a base monetária). Podemos então afirmar que, na identidade acima, os termos presentes no lado direito determinam $H_{t}$.

O comportamento do multiplicador monetário é definido por:

$$
m m_{t}=\frac{1+\Psi_{5, \mathrm{t}}}{1-\mathbb{d}_{\mathrm{t}}\left\{1-\left[\mathrm{ec}_{\mathrm{t}}-\frac{\left(\mathrm{ec}_{\mathrm{t}}-1\right)}{1+\mathrm{i}_{\mathrm{t}}}\right]\right\}}
$$

\footnotetext{
${ }^{27}$ Projetada nas simulações como uma fração da taxa básica. Tal fração foi gerada para cada ano pela extrapolação da tendência da relação TJLP/Selic presente nos dez anos anteriores.

28 Procedimentos paralelos aos usados para projetar $i_{\mathrm{P}} \mathrm{e} \mathrm{i}_{\mathrm{A}}$ foram aplicados para $\mathrm{i}_{\mathrm{A}} \mathrm{A} \mathrm{i}^{*}{ }_{\mathrm{p}}$.
} 
onde $\Psi_{5}$ é uma variável aleatória de média zero e distribuição normal, $0 \leq e c \leq 1$ é o percentual de depósitos compulsórios, e $0<\mathbb{d}<1$ (razão depósitos à vista nos bancos comerciais/meios de pagamento) no caso brasileiro tem sido uma função lentamente mutável do tempo. Tal fórmula apresenta as seguintes propriedades:

- Para ec $=1, \mathrm{~mm}=1+\Psi_{5, \mathrm{t}}$, qualquer que seja a taxa de juros;

- Para $\mathrm{i}=0, m m_{t}=\frac{1+\Psi_{5, \mathrm{t}}}{1-\mathrm{dl}}$; e

- Para $\mathrm{i} \rightarrow \infty, m m_{t}=\frac{1+\Psi_{5, \mathrm{t}}}{1-\mathbb{d}(1-\mathrm{ec})}$.

A velocidade-renda de circulação, por sua vez, será:

$$
V_{t}=\mathrm{e}^{\Psi_{6, t}} V_{t-1}
$$

onde $\Psi_{6}$ é uma variável aleatória com média zero e distribuição normal. Introduzindo as relações (51-53) em (46), temos:

$D L S P_{t-1}+N F S P_{t} \equiv \frac{Y_{t}}{m m_{t} V_{t}}+D g_{t}+e_{t}\left(P E B g_{t}^{*}-A E B g_{t}^{*}\right)-A_{t}$

Para determinar a estrutura patrimonial completa do setor público, considere a variável auxiliar tal que:

$$
F I N_{t}=D L S P_{t}-H_{t}+e_{t} A E B g_{t}^{*}
$$

Resulta:

$$
F I N_{t}=D g_{t}+e_{t} P E B g_{t}^{*}-A_{t}
$$

Considerando que a dinâmica dos ativos financeiros domésticos do setor público seja gerada por:

$$
A_{t}=\Xi_{t} D g_{t}
$$

onde $\Xi$ é uma variável de política, ${ }^{29}$ restará ainda decidir qual parte do hiato de recursos $F I N_{t}=\left(1-\Xi_{t}\right) D g_{t}+e_{t} P E B g_{t}^{*}$ será financiada mediante a emissão de dívida interna ou de passivo externo. ${ }^{30}$

\footnotetext{
${ }^{29}$ Para efeito de simulação, projetou-se $\delta$ a partir da extrapolação de sua tendência nos dez anos anteriores. Ao adotarmos tal comportamento para $\delta$, estamos assumindo a hipótese de que não haverá mudanças políticas bruscas na forma de gestão dos ativos financeiros domésticos seguida aproximadamente nos últimos dez anos.

${ }^{30}$ Nas simulações geradas pelo modelo, adotou-se a hipótese de manutenção do mix de financiamento previamente vigente ao longo de todo o período simulado.
} 


\section{Meta de superávit primário, impactos fiscais do crescimento da produção de petróleo e a taxa de investimento do setor público}

Para efeito das simulações que se tem em vista, a meta anual de superávit primário como proporção do PIB $(m s p)$ foi inicialmente calculada através da tradicional fórmula:

$$
m s p_{t}=d g_{t-1}\left(\frac{1+r_{t-1}^{M}}{1+g_{t-1}}-1\right)
$$

onde $d g=\frac{D L S P}{Y}$ é a razão dívida líquida do setor público/PIB, e $r_{t-1}^{M}$ é a taxa de juros real (implícita) incidente sobre essa dívida. ${ }^{31}$

Os cânones da sustentabilidade fiscal, contudo, informam que tais valores não devem ser estimados diretamente a partir dos valores correntes, mas sim corresponder aos valores estruturais dessas variáveis, despidas de variações conjunturais. Com este intuito, a meta de superávit primário foi suavizada mediante interpolação geométrica dos dados entre a meta de 2011 e a meta para 2020, gerada conforme uma aproximação da fórmula acima.

A partir desta meta, interessa investigar em que medida o crescimento da produção de petróleo prevista pode, elevando a folga fiscal, ajudar a aumentar a taxa de investimentos públicos (petróleo e não petróleo).

O orçamento do setor público em termos primários é definido por:

$$
O p_{t} \equiv\left(T_{t}-T r_{t}-C g_{t}\right)-P k_{t} I g_{t}
$$

A meta fiscal exige. ${ }^{32}$

$$
O p_{t} \geq m s p_{t} Y_{t}
$$

ou:

$$
\frac{\mathrm{Pk}_{\mathrm{t}} \mathrm{Ig}_{\mathrm{t}}}{\mathrm{Y}_{\mathrm{t}}} \leq \frac{\mathrm{T}_{\mathrm{t}}-\mathrm{Tr}_{\mathrm{t}}-\mathrm{Cg}_{\mathrm{t}}}{\mathrm{Y}_{\mathrm{t}}}-\mathrm{msp}_{\mathrm{t}}
$$

31 Calculada a partir da taxa de juros nominal implícita sobre a DLSP, definida como (Jg + RLEg)/DLSP.

32 Trabalha-se com a hipótese de necessidade de atendimento da meta "cheia", sem descontos para investimento. 
Convém agora aplicar:

$$
\begin{aligned}
& Y_{t} \equiv P_{t} Q_{t} \\
& T_{t} \equiv T p_{t}+T n p_{t}=t_{p, t} P p_{t} Q p_{t}+t_{n p, t} P n p_{t} Q n p_{t}+D V D_{p, t}+D V D_{n p, t} \\
& T r_{t} \equiv T r p_{t}+\operatorname{Trnp}_{t}=t r_{p, t} P p_{t} Q p_{t}+t r_{n p, t} P n p_{t} Q n p_{t} \\
& C g_{t} \equiv c g_{t} Y_{t} \\
& p k_{t}=\frac{P k_{t}}{P_{t}} \\
& d v d_{p, t}=\frac{D V D_{p, t}}{Y_{t}} ; \mathrm{e} \\
& d v d_{n p, t}=\frac{D V D_{n p, t}}{Y_{t}}
\end{aligned}
$$

onde $t$ é a alíquota tributária média, $c g$ é a participação do consumo governamental no PIB, $t r$ é a participação das transferências do governo para o setor privado ${ }^{33}$ (exceto juros) no PIB de cada setor, e $D V D_{p}$ e $D V D_{n p, t}$ são, respectivamente, os pagamentos de dividendos da Petrobras e das empresas financeiras estatais + Sistema Eletrobrás ao Tesouro, e P é o deflator do PIB. ${ }^{34}$ Resulta que a taxa máxima de investimento público em termos reais $\left(\frac{I g}{Q}\right)^{M A X}$ pode ser calculada a cada período como:

$$
\left(\frac{I g}{Q}\right)_{t}^{M A X}=\frac{p_{t}\left(t_{p, t}+d v d_{p, t}-t r_{p, t}\right)+\left(1-p_{t}\right)\left(t_{n p, t}+d v d_{n p, t}-t r_{n p, t}\right)-c g_{t}-m s p_{t}}{p k_{t}}
$$

Resta ainda verificar se essa taxa de investimento público é consistente com a trajetória de crescimento permitida pelo balanço de pagamentos. Conforme Harrod (1939), a taxa agregada de investimento consistente com o crescimento equilibrado entre demanda e capacidade produtiva é:

$$
\left(\frac{I}{Q}\right)_{t}=v_{t}\left(g_{t}+\delta\right)
$$

\footnotetext{
${ }^{33}$ No caso do setor petróleo, as transferências dizem respeito majoritariamente ao pagamento de royalties do governo (não da Petrobras) ao setor privado.

${ }^{34}$ Calculado como uma média ponderada entre o IPCA e o índice de preços do bem de capital.
} 
onde v é a relação capital/produto média. Como por definição a taxa agregada é a soma das taxas privada $\left(\frac{I p}{Q}\right)$ e pública de investimento, $\left(\frac{I p}{Q}\right)_{t}^{N}$, a taxa de investimento privada necessária para manter a economia em crescimento equilibrado entre produção e estoque de capital será de:

$$
\left(\frac{I p}{Q}\right)_{t}^{N}=v_{t}\left(g_{t}+\delta\right)-\left(\frac{I g}{Q}\right)_{t}^{M A X}
$$

O valor assim obtido permite avaliar se tal taxa pode ser atingida, uma vez que se leve em consideração os demais aspectos do cenário macroeconômico simulado (crescimento real do PIB, taxa de juros real, etc.). Permite averiguar portanto se, e em que medida, a política macroeconômica baseada no tripé meta de inflação + meta fiscal + câmbio flutuante administrado é compatível com o crescimento da produção de petróleo simulada. Seus determinantes principais estão resumidos no Quadro 3 abaixo:

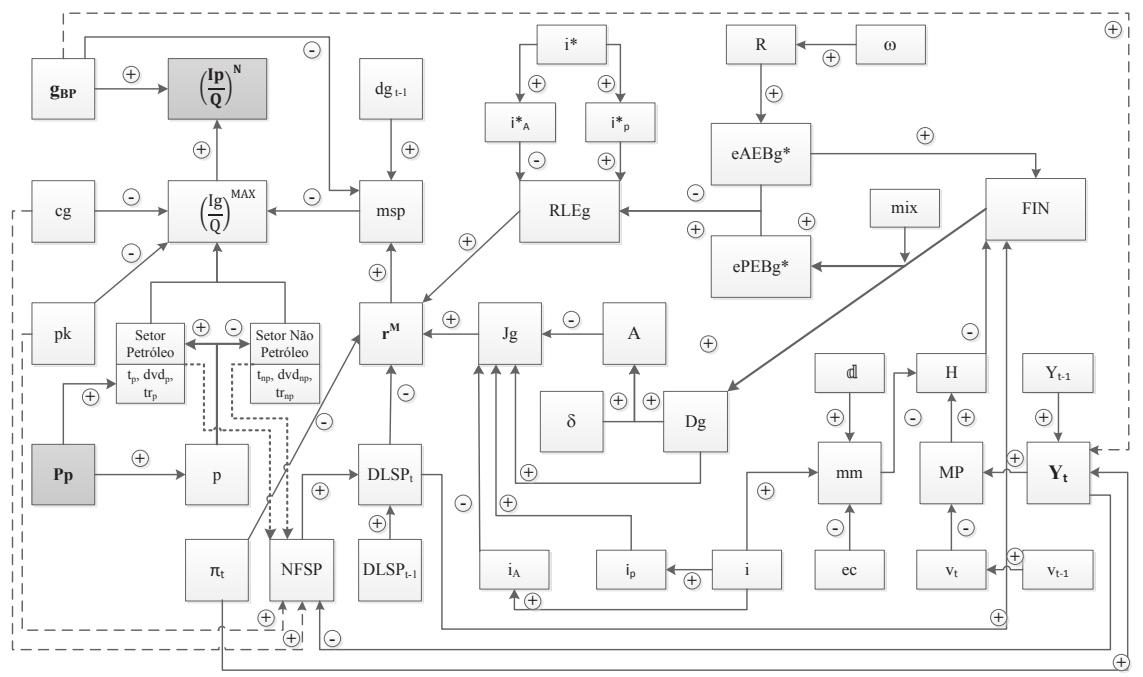

Quadro 3: Síntese dos principais determinantes da taxa de investimento privada mínima necessária para manter o crescimento equilibrado entre demanda e capacidade produtiva: 


\section{Considerações finais}

O presente artigo apresentou o modelo macroeconômico utilizado para a geração de simulações capazes de descrever a trajetória do potencial de crescimento da economia brasileira a partir do crescimento da produção de petróleo (inclusive da camada pré-sal). Supondo que o "tripé macroeconômico" atualmente vigente seja mantido até 2020, a modelagem serviu-se, além das tradicionais identidades da Contabilidade Nacional, de hipóteses comportamentais advindas de diversas tradições, como Thirlwall, Kaldor, Kalecki e Harrod. O principal esforço consistiu em tratar separadamente os setores petróleo e não petróleo, de maneira que se tornasse possível, através das simulações, avaliar o impacto do crescimento da produção de petróleo no potencial de crescimento do PIB brasileiro, em particular através do canal da restrição externa.

Também a introdução de taxas de câmbio e de juros endógenas rendeu resultados algo diversos dos comumente encontrados nos típicos modelos de crescimento com restrição externa. Em particular, convém ressaltar que mesmo admitindo (a la Kaldor) a possibilidade de que mudanças na taxa de câmbio real venham a exercer impactos sobre $g_{B P}$, o real alcance dessa medida fica limitado pela presença do regime de metas de inflação. Nos termos do modelo, depreciações cambiais, embora possam gerar efeitos positivos sobre o potencial de crescimento, também desencadeiam efeitos colaterais inflacionários. Esses, por sua vez, acionam políticas destinadas a conter a inflação (venda de divisas e/ou elevação dos juros) que, ao final, acabam por limitar o uso do câmbio como instrumento capaz de afrouxar a restrição externa e elevar o potencial de crescimento. Considerando as conhecidas limitações da estrutura produtiva brasileira, sua reduzida elasticidade-renda da demanda por exportações, e sua elevada elasticidade-renda da demanda por importações acabam por restringir severamente sua capacidade de crescimento sustentado. Tentativas de crescimento "em marcha forçada" acabam gerando "vôos de galinha" de crescimento, associado ao conhecido ciclo de endividamento externo.

Será o crescimento da produção de petróleo capaz de desatar esse nó górdio ao processo de crescimento sustentado da economia brasileira? A resposta do modelo acima desenvolvido é: "Em tese, é possível". Afinal, o crescimento da produção petrolífera implica aceleração do crescimento das exportações e (possivelmente) redução do 
crescimento das importações (petróleo). A consequente ampliação do raio de manobra da política econômica permitiria (mesmo dentro do atual tripé macroeconômico) acelerar a política de formação de reservas internacionais e/ou reduções adicionais dos juros. Ambas permitiriam maiores depreciações cambiais sem pressionar a meta de inflação, o que reforçaria as condições de competitividade da economia brasileira, elevando seu crescimento potencial.

Alguns óbices, contudo, impedem uma resposta afirmativa. Primeiro, é preciso quantificar os efeitos supracitados, de forma a ter ideia do real potencial de crescimento adicional permitido pelo crescimento da produção petrolífera. Neste campo, o modelo mostra, pouco surpreendentemente, que para além do crescimento da produção física, o comportamento do preço internacional do petróleo pode ser decisivo. Contudo, é preciso desmistificar a ideia de que um preço elevado do petróleo será necessariamente benéfico ao país, uma vez que ele se torne exportador líquido do recurso. Não se pode esquecer o fato de que o preço do petróleo continua a influir significativamente nos índices de preços domésticos. O potencial inflacionário resultante de um choque petrolífero, em um regime de metas de inflação, pode, em função da reação das políticas cambial e de juros, gerar forte apreciação cambial real (reforçada pelo fluxo cambial adicional do petróleo), com impacto deletério sobre o potencial de crescimento. Isto porque, como mostra o modelo, e em que pese o papel preponderante da Petrobras no processo, há limites para a capacidade da política de preços domésticos do petróleo absorver tais choques sem repasse.

Depois, é preciso evitar, por um lado, que o crescimento da demanda seja inadequado. Um crescimento excessivo recria o cenário de restrição externa em níveis ainda mais elevados de endividamento (o que, como mostra a experiência mexicana dos 80 , pode ser desastroso; vide Moreno-Brid e Ros, 2007). Por outro lado, um crescimento insuficiente é duplamente perigoso, pois, para além da dificuldade em manter taxas de desemprego baixas, causa: a) redução, via lei de Verdoorn, do crescimento da produtividade, com repercussões negativas sobre o processo de crescimento em si, podendo inclusive reforçar o nó górdio externo; b) criação um cenário de excedente estrutural de divisas que pode levar o país a mimetizar a experiência venezuelana (Furtado, 2008), criando uma espécie de "doença holandesa de laboratório", artificial. 
Ainda que, afinal, as restrições externa e de crescimento inadequado da demanda sejam superadas, é preciso verificar se, e em que medida, a manutenção de uma meta de superávit primário é consistente com a elevação da taxa de investimento público que um crescimento mais acelerado da economia por certo demandaria. É sabido que a consecução da meta de superávit primário tem se dado essencialmente à custa do investimento público. Como aponta o modelo, o crescimento da produção petrolífera, ao possibilitar a aceleração do crescimento, de um lado, e a redução dos juros, por outro, operam no sentido de ampliar o espaço disponível para tal investimento. O modelo aqui desenvolvido é então capaz de oferecer indicações acerca da suficiência ou não deste incremento, de modo a possibilitar uma expansão do estoque de capital físico consistente com o aumento do potencial de crescimento.

O modelo é suficientemente flexível para trabalhar diferentes cenários, conforme diversas combinações de variáveis exógenas lhe fossem imputadas. Mais que isso, em desenvolvimentos futuros, o modelo pode ser utilizado para simular trajetórias sob diferentes combinações de políticas macroeconômicas, tornando-as comparáveis.

No campo das limitações do modelo, há certamente inúmeras, mas a principal parece ser seu tratamento ainda excessivamente agregado. A falta de cuidadosa consideração das transformações das relações intersetoriais da cadeia petrolífera, que poderia ser mais bem apreendida a partir de uma matriz insumo-produto, impede maior precisão nas estimativas dos impactos nas elasticidades-renda das importações petróleo e não petróleo e dos coeficientes setoriais de Verdoorn. Contudo, no presente estágio da pesquisa a tentativa de combinar a (já extensa) estrutura do modelo com uma matriz insumo produto envolveria custos proibitivos de desenvolvimento. Optou-se então por manter um tratamento agregado sabidamente insuficiente, na expectativa de que as estimativas dessas variáveis que foram empregadas nas simulações não difiram exageradamente do que seria previsto por um modelo mais amplo. 


\section{Referências}

BCB. Manual de estatísticas fiscais publicadas pelo Departamento Econômico do Banco Central do Brasil. Brasília: Banco Central do Brasil, abril, 2012.

BANCHFLOWER, D.G. E OSWALD, A.J. “An introduction to the wage curve”. Journal of Economic Perspectives, vol. 9, No. 3 (verão), 1995.

BARBOSA, F.H. Uma estimativa do produto potencial no Brasil. Economia e Tecnologia. Ano 07, vol. 27, 2011, outubro-dezembro.

BEHRING, G. Análise crítica dos modelos de restrição externa na abordagem Kaldor-Thirlwall. Dissertação de Mestrado: IE/UFRJ, janeiro, 2013.

CIARLONE, A., PISELLI, P. E TREBESCHI, G. Emerging markets spreads and global financial conditions. Banca D'Italia: Tema di discussione del Servizio Studi, no. 637, junho, 2007.

FRANKEL, J.A. E FROOT, K.A. "Chartists, Fundamentalists, and Trading in the Foreign Exchange Market”. In: The American Economic Review, Vol. 80, No. 2, Papers and Proceedings of the Hundred and Second Annual Meeting of the American Economic Association (Maio), 1990, pp. 181-185.

FURTADO, C. Ensaios sobre a Venezuela: subdesenvolvimento com abundância de divisas. Rio de Janeiro: Centro Celso Furtado / Editora Contraponto, 2008.

GRAUWE, P. e DEWACHTER, H. "A chaotic model of the exchange rate: The role of fundamentalists and chartists”. In: Open Economies Review, Volume 4, Issue 4, 1993, pp 351-379.

HARROD, R.F. “An Essay in Dynamic Theory.” Economic Journal ,49 (Março), 1939.

IPEA. Como anda o investimento público no Brasil? Comunicados do IPEA, no. 126. Brasília: IPEA, 2011.

KALECKI, M. Theory of Economic Dynamic - An Essay of Cyclical and Long-Run Changes in Capitalist Economy. Londres: George Allen \& Unwin, 1954.

KEYNES, J. M. The General Theory of Employment, Interest and Money. Nova York: Harcourt, Brace, 1936.

LAVOIE, M. Foundations of Post-Keynesian Analysis. Aldershot: Edward Elgar, 1992.

LI, X., CHUNYANG, Z. e CHONGFENG, W. "The role of heterogeneous expectations in forward exchange market”. In: Applied Economics Letters, Vol. 20, Issue 5, 2013.

MARÇAL, E.F., NISHIJIMA, M. e MONTEIRO, W.O. Saldos Comerciais e Taxa de Câmbio Real: Uma Nova Análise do Caso Brasileiro. In: Economia, v.10, n.2, 2009, maio/agosto.

MINISTÉRIO DA FAZENDA. Carga Tributária Líquida. Informativos do Ministério da Fazenda. Brasília: Ministério da Fazenda, 2012.

MORANDI, L. E REIS, E.J. O estoque de capital fixo no Brasil: 1950-2002. Anais do XXXII Encontro Nacional de Economia. João Pessoa: Anpec, 2004.

MORENO-BRID, J.C. E ROS, J. Development and Growth in the Mexican Economy: A historical perspective. Oxford: Oxford University Press, 2009.

NASTEPAAD, C.W.M. "Technology, demand and distribution: a cumulative growth model with an application to the Dutch productivity growth slowdown". Cambridge Journal of Economics, no. $30,2006$.

ORAIR, R.O. Carga Tributária Brasileira - 2002/2012: estimação e análise dos determinantes da evolução recente. Monografia premiada com o XVII Prêmio Tesouro Nacional 2012. Brasília: Secretaria do Tesouro Nacional, 2012.

ROMER, D. "Keynesian macroeconomics without the LM curve". Journal of Economic Perspectives, vol. 14(2), primavera, 2000. 
SANTOLIM, R. e ANTIGO, M.F. Curvas de salários dinâmicas: um estudo dos determinantes das histerese do desemprego no Brasil. Texto para Discussão 368. Belo Horizonte: UFMG, 2009.

SANTOS, C.H.M, ORAIR, R.O., GOBETTI, S.W., FERREIRA, A.S., ROCHA, W.S., SILVA, H.L. E BRITTO, J.M. Uma metodologia de estimação da Formação Bruta de Capital Fixo das Administrações Públicas brasileiras em níveis mensais para o periodo 2002-2010. Brasília, IPEA: Texto para Discussão 1660, 2011.

SIMON, H.A. From Substantive to Procedural Rationality. In: Hahn, F., Hollis, M. (orgs.) (1979). Philosophy and Economic Theory. Oxford: Oxford University Press, 1958.

SOARES, J.J.S. E BARBOSA, F.H. Regra de Taylor no Brasil: 1999-2005. Trabalho apresentado no XXXIV Encontro Nacional de Economia da ANPEC. Salvador, 5 a 8 de dezembro, 2006.

SRAFFA, P. Production of Commodities by Means of Commodities. Cambridge: Cambridge University Press, 1960.

TAKAGI, S. Exchange Rate Expectations: A Survey of Survey Studies. In: Staff Papers - International Monetary Fund. Vol. 38, No. 1 (Março), 1991, pp. 156-183. 